\section{Postproduction Evaluations of Potted Asiatic and Oriental Hybrid Lilies}

\author{
Terril A. Nell and Ria T. Leonard \\ Department of Environmental Horticulture, University of Florida, Gainesville, \\ FL 32611
}

\section{A.A. De Hertogh \\ Department of Horticultural Science, North Carolina State University, Raleigh, NC 27695}

\author{
James E. Barrett \\ Department of Environmental Horticulture, University of Florida, Gainesville, \\ FL 32611
}

Additional index words. Lilium, potted flowering plant, senescence, transport

\begin{abstract}
Potted Lilium Asiatic hybrids 'Aristocrat', 'Horizon', and 'Polka' were evaluated following 3, 6, or 9 days of transport at 2, 7, or 13C. 'Aristocrat' and 'Horizon' withstood transport with little or no effect on floral bud opening. 'Polka' was the most sensitive cultivar to transport, where bud opening decreased $33 \%$ when transported at 13C for 9 days. Most floral buds opened on 'Aristocrat' $(90 \%$ to $98 \%)$, while fewer buds opened on 'Horizon' (37\% to $56 \%$ ) and 'Polka' (52\% to $90 \%$ ). Individual flower longevity and diameters were largely unaffected by transport. Plant longevity was reduced 4 to 7 days when transported for 9 days at $\geq 7 \mathrm{C}$ or for $>3$ days at 13C. Plant longevity averaged 16 days for 'Aristocrat' and 'Polka' and 12 days for 'Horizon'. 'Aristocrat' and the Oriental potted hybrid lily 'Star Gazer' were maintained at postproduction conditions of 18,21 , or $24 \mathrm{C}$ at 7 or $14 \mu \mathrm{mol} \cdot \mathrm{m}^{-2} \cdot \mathrm{s}^{-1}$ after being commercially transported for 4 days at 5 $\pm 2 C$. Postproduction conditions had no effect on floral bud opening of 'Aristocrat' $(98 \%$ to $99 \%$ ), while bud opening of 'Star Gazer' was reduced $17 \%$ at $24 \mathrm{C}$ compared to $18 \mathrm{C}$. Plants lasted 4 and 9 days longer at $18 \mathrm{C}$ than at 21 or 24C, respectively. Foliar discoloration was greatest at 24C. Irradiance level had no effect on the variables evaluated.
\end{abstract}

The success of newly introduced crops and cultivars for indoor use depends on their abilities to withstand periods of preshipping storage, transport, and low light conditions in retail and home environments. Asiatic and Oriental hybrid lilies, traditionally used as cut flowers, have gained popularity as indoor flowering potted plants (Aimone, 1986). To our knowledge, no information has been published on the handling requirements or postgreenhouse performance of Asiatic or Oriental hybrid lilies when used as potted plants. Therefore, research is needed to evaluate their performance as potted plants and to determine ways to prolong flower life and quality as influenced by postproduction factors. Cultivar comparisons are also necessary to ensure best selection for maximum performance.

Received for publication 19 Dec. 1994. Accepted for publication 9 Aug. 1995. Florida Agricultural Experiment Station Journal Series no. R-04281. We gratefully acknowledge the support provided by American Floral Endowment and Dutch Bulb Exporters Association. The assistance of Carolyn Bartuska and Lori Black also is appreciated. The cost of publishing this paper was defrayed in part by the payment of page charges. Under postal regulations, this paper therefore must be hereby marked advertisement solely to indicate this fact.
Previous work on Asiatic and Oriental lilies has concentrated on cut-flower vase life (Beattie et al., 1987; Pasterkamp, 1992; Swart, 1980). The objectives of our studies were to 1) determine the response of potted Asiatic and Oriental hybrid lilies to simulated transport and consumer conditions to evaluate their suitability as indoor potted plants; 2) identify factors that may prolong potted life; and 3) evaluate cultivar performance.

\section{Material and Methods}

Simulated transport(Expt. 1.). Lilium (Asiatic hybrids) 'Aristocrat', 'Horizon', and 'Polka' were planted on 5 Feb. 1990 at North Carolina State Univ. (NCSU), Raleigh, in 1.6liter(15-cm-diameter standard) pots. The growing medium consisted of equal volumes of shredded pine bark, sand, sphagnum peat, and sandy loam soil, plus dolomitic $\left(5.23 \mathrm{~kg} \cdot \mathrm{m}^{-3}\right)$ and hydrated lime $\left(1.3 \mathrm{~kg} \cdot \mathrm{m}^{-3}\right)$ mixed and sterilized. Three bulbs ( 12 to $14 \mathrm{~cm}$ in circumference) were placed in each pot and plants were forced using standard cultural practices (De Hertogh, 1989). Before the first floral bud began to show color $(\approx 1$ week before flowering), plants were sleeved, boxed, and transported within $24 \mathrm{~h}$ at $5 \pm 2 \mathrm{C}$ to the Univ. of Florida (UF), Gainesville. Plants were immediately placed in a glass greenhouse maintained at $21 \pm 3 \mathrm{C}$ until the first bud began to show color, indicating the optimal marketable stage (De Hertogh, 1989).
To simulate transport, plants were placed in closed boxes in darkness and maintained at 2,7 , or $13 \pm 1 \mathrm{C}$ for 3,6 , or 9 days. After transport, plants were placed in postproduction rooms maintained at $21 \pm 1 \mathrm{C}, 60 \%$ to $65 \%$ relative humidity $(\mathrm{RH})$, and $14 \mu \mathrm{mol} \cdot \mathrm{m}^{-2} \cdot \mathrm{s}^{-1}$ irradiance using cool-white fluorescent lamps for $12 \mathrm{~h} \cdot \mathrm{day}^{-1}$. Nontransported control plants were placed directly into rooms. A randomized complete-block design was used with six replications of two pots per experimental unit.

Postproduction temperature and irradiance (Expt. 2.). 'Aristocrat' and 'Star Gazer' (Oriental hybrids) were planted on 2 Feb. 1990 as described in Expt. 1, with the exception that one bulb (16 to $18 \mathrm{~cm}$ in circumference) per pot was used for 'Star Gazer'. Plants were forced using standard cultural practices (De Hertogh, 1989). Plants were sleeved and boxed at NCSU when the first bud began to color, but not open, and commercially transported for 4 days at $5 \pm 2 \mathrm{C}$ from NCSU to UF. Upon arrival, plants were placed directly into postproduction rooms maintained at 18,21 , or $24 \pm 1 \mathrm{C}, 60 \%$ to $65 \% \mathrm{RH}$, and 7 or 14 $\mu \mathrm{mol} \cdot \mathrm{m}^{-2} \cdot \mathrm{s}^{-1}$ irradiance provided by cool-white fluorescent lamps for $12 \mathrm{~h} \cdot \mathrm{day}^{-1}$. A randomized complete-block design with three replications of two pots per experimental unit was used. This study was repeated (planting date 21 Feb. 1990). No statistical differences were found between the two studies; therefore, analyses combined data from both studies.

Data records. Data recorded for both experiments included 1) number of buds that opened, abscised, or aborted; 2) flower diameter; 3) individual flower longevity; and 4) plant longevity. Individual flower longevity was the interval between anthesis and senescence, and plant longevity was the interval between placement into rooms and senescence of all flowers. Data were tested by analysis of variance and orthogonal comparisons were used to examine differences among means. Dunnett's test $(P \leq 0.05)$ was used to test differences from the control. Before analysis, percentage data were transformed [angle $=$ $\arcsin$ (square root \%)] when necessary to stabilize the variance.

\section{Results and Discussion}

Simulated transport (Expt. 1). The threeway interaction of cultivar $\times$ transport temperature $\times$ transport duration was significant for percent buds that opened (Table 1). Floral buds either developed normally, abscised, or never opened and remained on the plant and eventually dried up (aborted). Most floral buds on 'Aristocrat' opened, regardless of transport temperature and duration, while fewer buds opened on 'Polka' and 'Horizon' (Table 2). Percent bud opening was lowest in 'Horizon' $(\leq 56 \%)$ at all treatments, including the control. Floral buds that did not open on 'Horizon' mostly aborted (44\%), with few buds abscising (8\%). 'Polka' was the most sensitive cultivar to simulated transport conditions. For example, transporting 'Polka' for 9 days at $13 \mathrm{C}$ reduced bud opening by $33 \%$, compared to $8 \%$ in the other cultivars. 
Table 1. Significance levels for effects of cultivar and simulated transport temperature and duration on floral bud opening, flower diameter, flower longevity, and plant longevity of potted Asiatic hybrid lilies 'Aristocrat', 'Horizon', and 'Polka'.

\begin{tabular}{lccccc}
\hline \hline Source & df & $\begin{array}{c}\text { Percent } \\
\text { buds } \\
\text { open }^{\mathbf{z}}\end{array}$ & $\begin{array}{c}\text { Flower } \\
\text { longevity } \\
\text { (days) }\end{array}$ & $\begin{array}{c}\text { Flower } \\
\text { diam } \\
(\mathrm{cm})\end{array}$ & $\begin{array}{c}\text { Plant } \\
\text { longevity } \\
\text { (days) }\end{array}$ \\
\hline Block & 5 & $\mathrm{NS}$ & $\mathrm{NS}$ & $\mathrm{NS}$ & $\mathrm{NS}$ \\
Cultivar (C) & 2 & 0.0001 & 0.0001 & 0.0001 & 0.0001 \\
Temperature (T) & 2 & 0.0001 & NS & NS & 0.0001 \\
C $\times$ T & 4 & 0.0124 & NS & NS & NS \\
Duration (D) & 2 & 0.0014 & NS & NS & 0.0001 \\
C $\times$ D & 4 & NS & NS & NS & NS \\
T $\times$ D & 4 & NS & NS & 0.0009 & 0.0001 \\
C $\times$ T $\times$ D & 8 & 0.0284 & NS & NS & NS \\
\hline
\end{tabular}

${ }^{\mathrm{z}}$ Analysis done on transformed data.

NsNonsignificant at $P \leq 0.05$.

Table 2. Influence of simulated transport temperature and duration and cultivar on percent buds open of potted Asiatic hybrid lilies 'Aristocrat', 'Horizon', and 'Polka'.

\begin{tabular}{|c|c|c|c|c|}
\hline \multirow{2}{*}{$\begin{array}{l}\text { Transport } \\
\text { duration } \\
\text { (days) }\end{array}$} & \multirow{2}{*}{$\begin{array}{c}\text { Transport } \\
\text { temp } \\
\left({ }^{\circ} \mathrm{C}\right)\end{array}$} & \multicolumn{3}{|c|}{ Buds open (\%) } \\
\hline & & Aristocrat & Horizon & Polka \\
\hline Control & -- & 98 & 47 & 85 \\
\hline \multirow[t]{3}{*}{3} & 2 & 97 & 41 & 79 \\
\hline & 7 & 96 & 51 & 78 \\
\hline & 13 & 98 & 42 & 65 \\
\hline Significance & & NS & NS & $\mathrm{L}^{*}$ \\
\hline \multirow[t]{3}{*}{6} & 2 & 96 & 56 & 90 \\
\hline & 7 & 94 & 53 & 76 \\
\hline & 13 & 97 & 37 & 65 \\
\hline Significance & & NS & $\mathrm{L}^{*}$ & $\mathrm{~L}^{* * *}$ \\
\hline \multirow[t]{3}{*}{9} & 2 & 99 & 46 & $58^{z}$ \\
\hline & 7 & 90 & 45 & 78 \\
\hline & 13 & 90 & 39 & $52^{z}$ \\
\hline Significance & & $\mathrm{L}^{* * *}$ & NS & $\mathrm{Q}^{* * *}$ \\
\hline
\end{tabular}

${ }^{2}$ Significantly different from control using Dunnett's test at $P \leq 0.05$.

Ns, *****Nonsignificant or significant at $P \leq 0.05$ or 0.001 , respectively; $\mathrm{L}=$ linear, $\mathrm{Q}=$ quadratic.

Individual flower longevity was unaffected by the simulated transport treatments (Table 1). Since most floral buds opened after transport, there was no delayed effect of transport on flower longevity. There were, however, small but significant differences among cultivars (Table 1). Flower longevity averaged 5 days for 'Aristocrat' and 'Polka' and 4 days for 'Horizon'.

Differences observed in flower diameters due to transport effects were negligible $(<1.0$ $\mathrm{cm})$, and none were different from the control, indicating flowers reach their full size potential under the stress of transport and lowirradiance conditions (Table 3). Flower diameters differed significantly among cultivars $(P$ $\leq 0.0001)$. 'Aristocrat' had the largest diameters $(14.0 \mathrm{~cm})$, followed by 'Polka' $(12.6 \mathrm{~cm})$ and 'Horizon' (10.6 cm).

Transporting lilies caused an $11 \%$ to $39 \%$ reduction in plant longevity (Table 3 ). Longevity was significantly reduced when maintained $>3$ days at $13 \mathrm{C}$ and when transported for 9 days at $7 \mathrm{C}$ or above. The greatest reduction in plant longevity was 7 days, which occurred when transported for 9 days at 13C. Plant longevity averaged 16 days for 'Aristocrat' and 'Polka' and 12 days for 'Horizon'. The lower plant longevity of 'Horizon' reflects the fewer buds that opened.

Postproduction temperature and irradiance (Expt. 2). No interactions were significant on the measured variables except for the cultivar $\times$ temperature interaction for percent buds opened ( $P \leq 0.0166$ ). Most buds on 'Aristocrat' opened (98\% to $99 \%)$ under all postproduction conditions, while fewer buds opened on 'Star Gazer' (55\% to 72\%), especially at $24 \mathrm{C}$ (Table 4 ). Bud opening was 5 and 17 percentage points lower at 21 and $24 \mathrm{C}$, respectively, than at $18 \mathrm{C}$. Most buds that did not open on 'Star Gazer' abscised. Irradiance had no effect on percent bud opening.

Flower diameter was unaffected by postproduction conditions, while differences between cultivars were significant $(P \leq 0.0001)$. Flower diameters of 'Aristocrat' were 12.8 and $16.3 \mathrm{~cm}$ for 'Star Gazer'. Lower temperatures resulted in longer individual flower longevity $(P \leq 0.0001)$. Flower longevity averaged 7,6 , and 5 days at 18,21 , and $24 \mathrm{C}$, respectively. Flower longevity averaged 6 days for 'Aristocrat' and 7 days for 'Star Gazer' $(P$ $\leq 0.0001$ ).

Plant longevity differed among temperatures $(P \leq 0.0001)$. Longevity averaged 28,23 , and 19 days at 18,21 , and $24 \mathrm{C}$, respectively. An increase in plant longevity of 4 to 9 days was achieved when plants were maintained at $18 \mathrm{C}$ compared to 21 and $24 \mathrm{C}$, respectively.

Lower leaves on 'Aristocrat' yellowed, while leaves on 'Star Gazer' turned brown. Maintaining plants at 24C further increased foliar discoloration. Although not quantified, $\approx 5 \%$ of the leaves yellowed on 'Aristocrat' at $18 \mathrm{C}$ and $\approx 30 \%$ at $24 \mathrm{C}$. Leaf browning of 'Star Gazer' was $\approx 5 \%$ at $18 \mathrm{C}$ and $\approx 90 \%$ at $24 \mathrm{C}$. The cause of these foliar problems is not known.
Table 3. Effects of simulated transport temperature and duration on flower diameter and plant longevity of potted Asiatic hybrid lilies 'Aristocrat', 'Horizon', and 'Polka'.

\begin{tabular}{lccc}
\hline $\begin{array}{l}\text { Transport } \\
\text { duration } \\
\text { (days) }\end{array}$ & $\begin{array}{c}\text { Transport } \\
\text { temp } \\
\left({ }^{\circ} \mathrm{C}\right)\end{array}$ & $\begin{array}{c}\text { Flower } \\
\text { diam } \\
(\mathrm{cm})\end{array}$ & $\begin{array}{c}\text { Plant } \\
\text { longevity } \\
\text { (days) }\end{array}$ \\
\hline Control & --- & 13.3 & 18 \\
3 & 2 & 13.0 & 16 \\
& 7 & 12.9 & 16 \\
Significance & 13 & 12.4 & 16 \\
6 & 2 & $\mathrm{NS}$ & $\mathrm{NS}$ \\
& 7 & 13.0 & 16 \\
& 13 & 13.3 & 16 \\
Significance & & $\mathrm{NS}$ & $\mathrm{L}^{* *}$ \\
9 & 2 & 12.7 & 16 \\
& 7 & 12.5 & $14^{\mathrm{z}}$ \\
Significance & 13 & 13.1 & $11^{\mathrm{z}}$ \\
\hline
\end{tabular}

${ }^{{ }^{2}}$ Significantly different from control using Dunnett's test at $P \leq 0.05$.

ns, *, **, **** Nonsignificant or significant at $P \leq 0.05$, 0.01 , or 0.001 , respectively; $\mathrm{L}=$ linear.

Table 4. Effects of cultivar and postproduction temperature on percent buds open on potted Asiatic ('Aristocrat') and Oriental ('Star Gazer') hybrid lilies.

\begin{tabular}{lcc}
\hline & $\begin{array}{c}\text { Postproduction } \\
\text { temp } \\
\left({ }^{\circ} \mathrm{C}\right)\end{array}$ & $\begin{array}{c}\text { Buds open } \\
(\%)^{\mathrm{z}}\end{array}$ \\
\hline Aristocrat & 18 & 99 \\
& 21 & 99 \\
Significance & 24 & 98 \\
Star Gazer & 18 & $\mathrm{NS}$ \\
& 21 & 72 \\
Significance & 24 & 67 \\
\end{tabular}

${ }^{\mathrm{z}}$ Data pooled over postproduction irradiance.

Ns, ** Nonsignificant or significant at $P \leq 0.01$; $\mathrm{L}=$ linear.

The higher temperatures appear to be accelerating senescence, possibly due to carbohydrate depletion as shown with Lilium longiflorum (Miller et al., 1993).

Based on the range of conditions tested, Asiatic hybrid lilies can perform well as flowering potted plants provided cultivar selection is considered and proper transport and postproduction conditions are maintained. Our tests demonstrate that most of the cultivars evaluated can withstand a range of transport conditions with little or no effect on floral bud opening. However, a transport period of 3 to 6 days at 2 to $7 \mathrm{C}$ would be optimum to maximize longevity. Floral bud opening appears to be more a function of cultivar variation than postproduction environment. Plant longevity ranged from 2 to 4 weeks under the conditions tested, an acceptable length of time for a potted flowering plant. 'Aristocrat' and 'Polka' performed better than 'Horizon' or 'Star Gazer' due to the greater percentage of buds that opened.

Further work is needed to evaluate performance of potted hybrid lilies. Other factors, such as production and storage conditions, may influence postproduction performance, as demonstrated with Easter lilies (Healy et al., 1979; Prince et al., 1987; Staby and Erwin, 1977). 


\section{Literature Cited}

Aimone, T. 1986. Culture notes. GrowerTalks 50:16. Beattie, D.J., K.B Evensen, and J.W. White. 1987. Effect of different shade levels on flowering, bud abortion, and vase life of hybrid garden lilies. HortScience 22:1051.

De Hertogh, A.A. 1989. Holland bulb forcer's guide. The Intl. Flower-Bulb Centre, Hillegom, The Netherlands.
Healy, W.E., R.D. Heins, and H.F. Wilkins. 1979. Short-term storage of Lilium longiflorum Thunbergia in the "puffy" flower stage of development. Minn. State Florists Bul., Feb. 1979.

Miller, W.B, P.A. Hammer, and T.I. Kirk. 1993. Reversed greenhouse temperatures alter carbohydrate status in Lilium longiflorum Thunb. 'Nellie White'. J. Amer. Soc. Hort. Sci. 118:736-740. Pasterkamp, H.P. 1992. Quality aspects in variety testing of lilies. Acta Hort. 325:349-354.
Prince, T.A., M.S. Cunningham, and J.S. Peary. 1987. Floral and foliar quality of potted Easter lilies after STS or phenidone application, refrigerated storage, and simulated shipment. J. Amer. Soc. Hort. Sci. 112:469-473.

Staby, G.L. and T.D. Erwin. 1977. The storage of Easter lilies. Florists Rev. 161(4162):38.

Swart, A. 1980. Quality of Lilium 'Enchantment' flowers as influenced by season and silver thiosulfate. Acta Hort. 113:45-49. 